\title{
BANCO DE DADOS GEOGRÁFICOS PARA GESTÃO INTEGRADA APLICADA AO SANEAMENTO BÁSICO EM UM BAIRRO DA METRÓPOLE DA AMAZÔNIA
}

\author{
Ermeson Freitas da Silva \\ Universidade do Estado do Pará (UEPA), Centro de Ciências Naturais e Tecnologia \\ Engenheiro Ambiental, Belém, PA, Brasil \\ ermesonfreitasdasilva@gmail.com
}

Rafael Ribeiro Meireles Universidade do Estado do Pará (UEPA), Centro de Ciências Naturais e Tecnologia Engenheiro Ambiental, Belém, PA, Brasil rafarm1997@gmail.com

Aline Souza Sardinha

Universidade do Estado do Pará (UEPA), Centro de Ciências Naturais e Tecnologia Professora do Departamento de Engenharia Ambiental, Engenheira Sanitarista/Mestre em Geologia Belém, PA, Brasil alinesardinha@uepa.br

Edgleuberson Guimarães Rocha Companhia de Saneamento do Pará (COSANPA), Unidade de Serviço de Coleta e Tratamento de Esgoto Engenheiro Sanitarista, Belém, PA, Brasil edgleuberson@gmail.com

\begin{abstract}
RESUMO
O saneamento básico visa alcançar quatro vertentes de prestação de serviços essenciais à sociedade: abastecimento de água, esgotamento sanitário, drenagem de águas pluviais e manejo de resíduos sólidos. Nesse sentido, desenvolver um banco de dados geográficos (BDG) auxiliará como ferramenta para uma gestão integrada por parte dos gestores do saneamento. O objetivo deste trabalho é propor um BDG contendo informações do saneamento e das características urbanas e ambientais para melhorar a gestão integrada no bairro da Marambaia em Belém/PA. Para isso, adquiriu-se dados em órgãos públicos e prestadores de serviços de saneamento, nos formatos espaciais dwg, pdf e shp. Em seguida, foram processados e validados pelas ferramentas AutoCAD e ArcMap, e posteriormente, armazenados no BDG por meio do PostgreSQL e sua extensão espacial PostGIS os quais foram gerenciados pelo pgAdmin 4, resultando na sistematização em um único BDG contendo dados para geração de tabelas e mapas cartográficos do saneamento e características urbanas e ambientais. O BDG mostrou-se um excelente instrumento para a gestão integrada do saneamento, pois permite produzir, verificar e analisar de forma conjunta e segura informações e dados de saneamento contribuindo para tomar decisões e mitigar problemas.
\end{abstract}

Palavras-chave: Saneamento Básico. Base de Dados. Gestão Integrada.

\section{GEOGRAPHIC DATABASE FOR INTEGRATED MANAGEMENT APPLIED TO BASIC SANITATION IN A NEIGHBORHOOD OF THE AMAZON METROPOLIS}

\begin{abstract}
Basic sanitation aims to achieve four aspects of providing essential services to society: water supply, sanitary sewage, rainwater drainage and solid waste management. In this sense, developing a geographic database (BDG) will help as a tool for integrated management by sanitation managers. The objective of this work is to propose a BDG containing information on sanitation and urban and environmental characteristics to improve integrated management in the neighborhood of Marambaia in Belém / PA. For this, data was acquired from public
\end{abstract}

$\begin{array}{llllll}\text { Caminhos de Geografia } & \text { Uberlândia-MG } & \text { v. 22, n. } 83 & \text { out./2021 } & \text { p. 86-103 } & \text { Página } 86\end{array}$


agencies and health service providers, in spatial formats dwg, pdf and shp. Then, they were processed and validated by the AutoCAD and ArcMap tools, after, stored in the BDG through PostgreSQL and its PostGIS spatial extension both managed by pgAdmin 4, resulting in the systematization in a single BDG containing data for the generation of tables and cartographic maps sanitation and urban and environmental characteristics. The BDG proved to be an excellent instrument for integrated sanitation management, as it allows to produce, verify and analyze jointly and safely sanitation information and data, helping to make decisions and mitigate problems.

Keywords: Basic Sanitation. Data Base. Integrated Management.

\section{INTRODUÇÃO}

Os serviços de saneamento básico são fundamentais para a promoção da saúde pública. A água disponível em quantidade e qualidade adequada estabelece fator de prevenção de doenças e em quantidade insuficiente ou qualidade imprópria para consumo humano poderá ser geradora de doenças. Isso pode ser observado também nos demais serviços de esgotamento sanitário, drenagem urbana e resíduos sólidos quanto à inexistência e pouca eficiência (HELLER; LISBOA; SILVEIRA, 2013).

Em todo o mundo, 3 em cada 10 pessoas (2,1 bilhões) não têm acesso à água potável e disponível em casa, e 6 em cada 10, ou 4,5 bilhões, carecem de saneamento seguro, de acordo com o novo relatório da Organização Mundial da Saúde (OMS) e do Fundo das Nações Unidas para a Infância (UNICEF) do ano de 2017. No Brasil, o país ainda apresenta quase 35 milhões de brasileiros sem acesso à água tratada, quase 100 milhões de brasileiros sem coleta de esgoto (47,6\% da população) e apenas $46 \%$ dos esgotos gerados no país são tratados, segundo dados do Sistema Nacional de Informações sobre Saneamento (SNIS, 2017).

Nesse Sentido, a Lei $n^{\circ} 11.445 / 2007$ prevê a criação do Sistema Nacional de Informações em Saneamento Básico (SINISA) como substituto do atual SNIS e de instrumento para que o titular do serviço estabeleça a política nacional de saneamento, de modo a sistematizar os dados, disponibilizar estatísticas de indicadores, além do monitoramento e avaliação dos prestadores de serviços, organizando um sistema de informações para o saneamento básico. Prevê ainda, a criação do Plano Municipal de Saneamento Básico (PMSB) que apoie o planejamento desses serviços prestados, pois ainda é precária sua universalização (BRASIL, 2007).

Nessa perspectiva, foi promulgada a Lei $n . .7 .731 / 2013$ que dispõe sobre a política estadual de saneamento básico, a qual institui no art. $4^{\circ}$ os princípios do serviço de saneamento básico e no inciso II a integralidade, que proporciona à população o acesso e máxima eficácia das ações e resultados. No artigo $31^{\circ}$ fica criado o Sistema de Informações de Saneamento do Estado do Pará - SISEP, articulado com o SINISA, para integrar as informações de saneamento básico dos municípios paraenses e no inciso IX, alínea c, tem-se que as informações do Sistema SISEP devem ser públicas e acessíveis a todos facilitando a elaboração dos planos de saneamento básico ao nível regional e municipal (PARÁ, 2013).

De acordo com o 'Ranking do Saneamento nas 100 Maiores Cidades', elaborado pelo Instituto Trata Brasil (ITB), com base nos dados do SNIS de 2017, há 3 municípios do estado do Pará localizados na parte inferior do ranking quanto ao saneamento, a saber: o município de Belém na $90^{a}$, Santarém na 97 e Ananindeua na 99a posição. Desse modo, o Plano Municipal de Saneamento de Belém, no seu volume II de 2014, prevê a criação de um sistema de cadastro georreferenciado da área urbana contendo informações acerca do saneamento com o objetivo principal de promover o georreferenciamento, a rastreabilidade e modernização dos sistemas de água e esgoto, através de ações de cadastro, mapeamento, diagnóstico, capacitação e regulamentação das atividades, no entanto, o sistema não é integrado com os órgãos afins (PMSB II, 2014).

Para essa integração é necessário buscar instrumentos que permitam a visualização e elaboração de um sistema gerencial de informações que contemple os quatro eixos do saneamento básico e as características urbanas e ambientais (HILGERT, 2014). Almeida (2017) reforça a potencialidade do banco de dados geográficos em organizar repositório de dados espaciais para atender usuários e

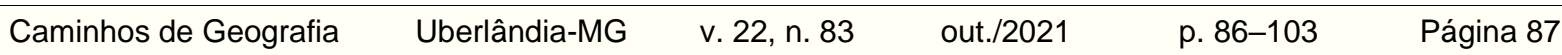


gestores públicos proporcionando eficiência na tomada de decisão e a oportunidade de realizar estudos ambientais e sociais aliados a variável tempo.

Até meados dos anos 60 , os dados eram mantidos aleatoriamente em arquivos, normalmente como partes integrantes das atividades das organizações. Logo, surgiram os primeiros Sistemas Gerenciadores de Bancos de Dados (SGBD) comerciais, provendo armazenamento dos dados de forma independente da aplicação, contudo, sem mecanismos de acesso eficientes, impulsionados principalmente por empresas como a International Business Machines Corporation (IBM), Oracle Corporation e Sybase (BOSCARIOLI, et al. 2006). Esta iniciativa teve como objetivo a automação de escritório, onde as empresas buscavam reduzir custos em relação à contratação de funcionários e seus serviços de armazenar e organizar alta variedade e quantidade de arquivos, por isso buscaram-se meios menos custosos e eficientes de armazenamento de dados.

Em vista disto, é de fundamental importância desenvolver um banco de dados geográfico que integre camadas de informações espaciais do saneamento e das características urbanas e ambientais do município de Belém no Estado do Pará, em um sistema gerencial que torne possível a análise e gestão integrada, pelos órgãos públicos, bem como das empresas públicas e privadas prestadoras de serviços relacionados ao saneamento básico.

\section{METODOLOGIA}

\section{Área de Estudo}

A área selecionada para este estudo foi o bairro da Marambaia, pois é um dos bairros que apresenta serviços do saneamento básico entre os maiores percentuais de cobertura, e acessibilidade às informações pelos órgãos gestores, além de conter a principal Unidade de Serviço de Coleta e Tratamento de Esgoto (USTE) do município. Localizado na porção nordeste (NE) do município de Belém do estado do Pará integrante da Amazônia Legal, conforme Figura 1, o bairro compõe os Distritos Administrativos Sacramenta (DASAC) e Entroncamento (DAENT), e possui 66.708 habitantes (IBGE, 2012).

Figura 1 - Marambaia (Belém-PA): Localização do bairro, 2019.

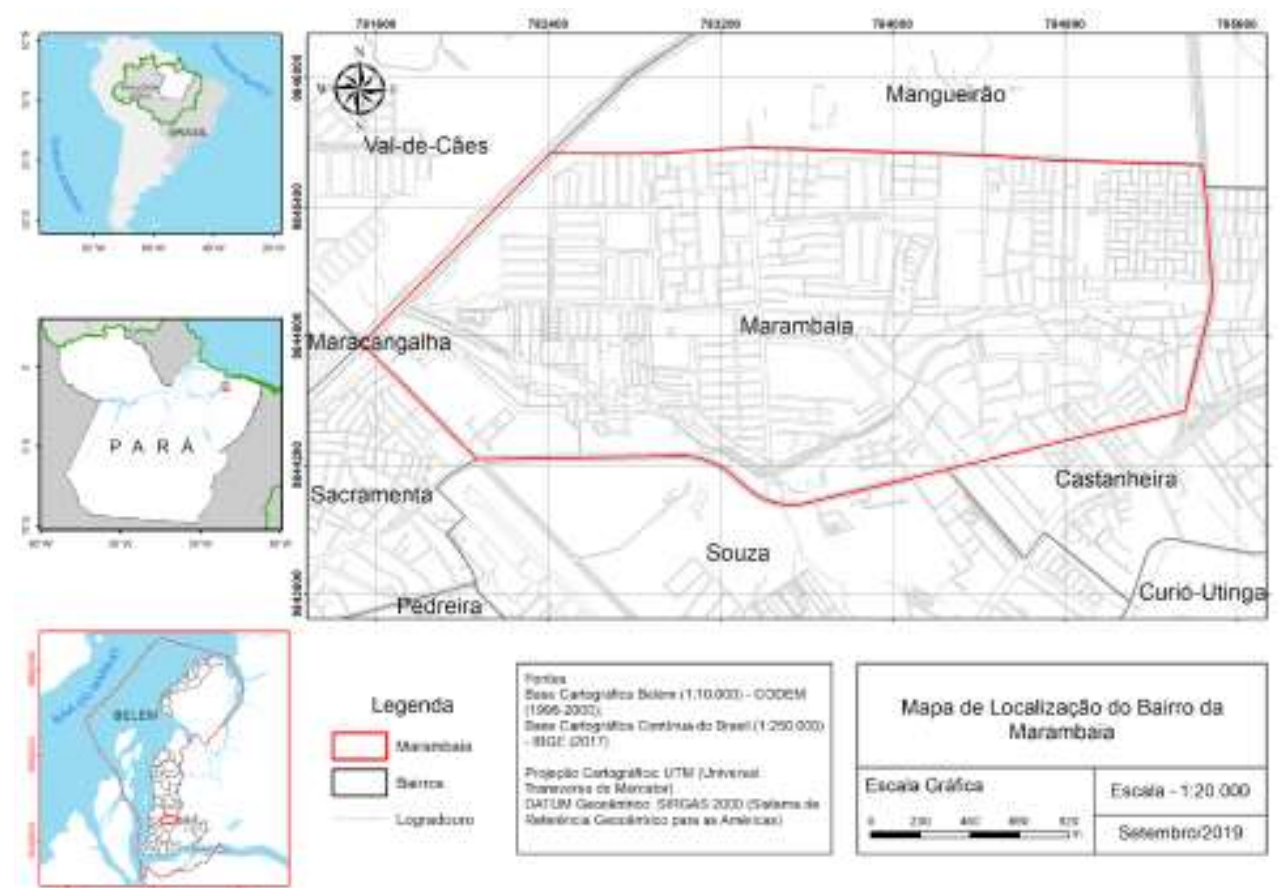

Fonte - Autores (2019).

$\begin{array}{lllll}\text { Caminhos de Geografia } & \text { Uberlândia-MG } & \text { v. 22, n. } 83 & \text { out./2021 } & \text { p. 86-103 }\end{array}$




\section{Fonte dos Dados}

Para construir uma base de dados e compor o BDG "saneamento_marambaia", foram reunidas informações espaciais nos formatos shapefile (shp.), drawing (dwg.), Portable Document Format (pdf.) e Comma separated values (csv.) das redes de água e esgoto, drenagem urbana e resíduos sólidos. As informações sobre as características urbanas e ambientais da Marambaia são administradas pela Companhia de Desenvolvimento de Belém (CODEM) e tais informações são disponibilizadas via digital, pelo Portal da Prefeitura de Belém, através de mapas disponíveis no formato pdf. gerado a partir do Cadastro Técnico Multifinalitário (CTM) de Belém, realizado em junho de 1998 e com isso, utilizou-se deles para extração das camadas. Usaram-se ainda informações referente ao estudo realizado por Guimarães et al. (2017) em parceria com a Faculdade Estácio de Belém - Campus IESAM, e também, no Laboratório de Geoprocessamento (LABGEO) do Instituto Evandro Chagas (IEC) e da Secretaria Municipal de Meio Ambiente de Belém (SEMMA), o qual mapeou os pontos e áreas de alagamento de Belém no período de 2015 a 2017.

Os dados do Serviço de Abastecimento de Água (SAA) e do Serviço de Esgotamento Sanitário (SES) da Marambaia foram adquiridos na COSANPA, no Complexo São Brás, responsável pela gestão do SAA e na Unidade de Serviço de Coleta e Tratamento de Esgoto (USTE) localizada no bairro de estudo, responsável pela gestão do SES, respectivamente. Com relação ao sistema de drenagem de águas pluviais e coleta seletiva foram obtidos na Secretaria Municipal de Saneamento (SESAN), e os de resíduos sólidos domiciliares (RDO) na empresa BA Meio Ambiente Ltda, que é a empresa terceirizada responsável pela coleta dos resíduos sólidos. Foi obtido no portal do Instituto Brasileiro de Geografia e Estatística (IBGE), a base de informações do censo demográfico de 2010 dos resultados do universo por setor censitário do IBGE, com a malha espacial dos setores, abrangendo o bairro da Marambaia.

Além destes, utilizaram-se imagens de SAR (synthetic aperture radar) do satélite Alos Palsar de 12,5 metros de resolução contendo informações sobre o modelo digital de elevação baixados do Alaska Satellite Facility (ASF) Distributed Active Archive Center (DAAC) do qual pode-se extrair a hipsometria da área de estudo.

\section{Sistematização dos Dados}

Na primeira etapa, os dados em dwg. da rede de esgoto não estavam georreferenciados, portanto, utilizaram-se técnicas de georreferenciamento no AutoCAD 2018 e posteriormente foram manipulados no ArcMap 10.6.1. Ainda, os mapas em pdf. disponibilizados pela CODEM, foram importados para o AutoCAD conservando suas geometrias e camadas, transformando-os no formato geométrico e com camadas separadas e editáveis. Em seguida, por meio da ferramenta "Alinhar" as geometrias foram georreferenciadas criando três pontos de controles com coordenadas adquiridas nos próprios mapas em pdf. Após a criação dos pontos de controle, as camadas foram alinhadas e redimensionadas relacionando-os com a camada grid a qual contém as coordenadas geográficas do mapa.

Na segunda etapa, os arquivos em dwg. após o georreferenciamento, foram convertidos para o formato geodatabase, que apresenta a vantagem de conservar todas as características dos arquivos dwg. separando suas camadas, em seguida, cada camada foi exportada para shapefile, exceto as camadas annotation (informações de texto), estas foram acrescentadas aos arquivos shapefile por meio da ferramenta Join Data no ArcMap. Esta ferramenta, foi utilizada também para unir as informações da malha espacial dos setores censitários com a tabela Domicílio_01 PA.csv que contém as variáveis relacionadas aos domicílios particulares permanentes atendidos pelos serviços do saneamento e dessa forma gerar mapas temáticos. A classificação da cobertura do saneamento básico dos setores censitário por domicílios permanentes foi classificada da seguinte forma: $0 \%$ a 20\% como "Péssima"; maior que $20 \%$ a $40 \%$ como "Ruim"; maior que $40 \%$ a $60 \%$ como "Boa"; maior que $60 \%$ a $80 \%$ como "Ótima" e maior que $80 \%$ a $100 \%$ como "Excelente".

$\begin{array}{lllll}\text { Caminhos de Geografia } & \text { Uberlândia-MG } & \text { v. 22, n. } 83 & \text { out./2021 } & \text { p. 86-103 }\end{array}$


Para criar e gerenciar o banco de dados relacional utilizou-se a ferramenta pgAdmin 4 versão 4.9 e foram adicionadas as extensões espaciais PostGIS, topology e pgRouting. O nome dado ao banco foi "saneamento marambaia". A Figura 2 resume os procedimentos metodológicos adotados.

Figura 2 - Metodologia da pesquisa, 2019.

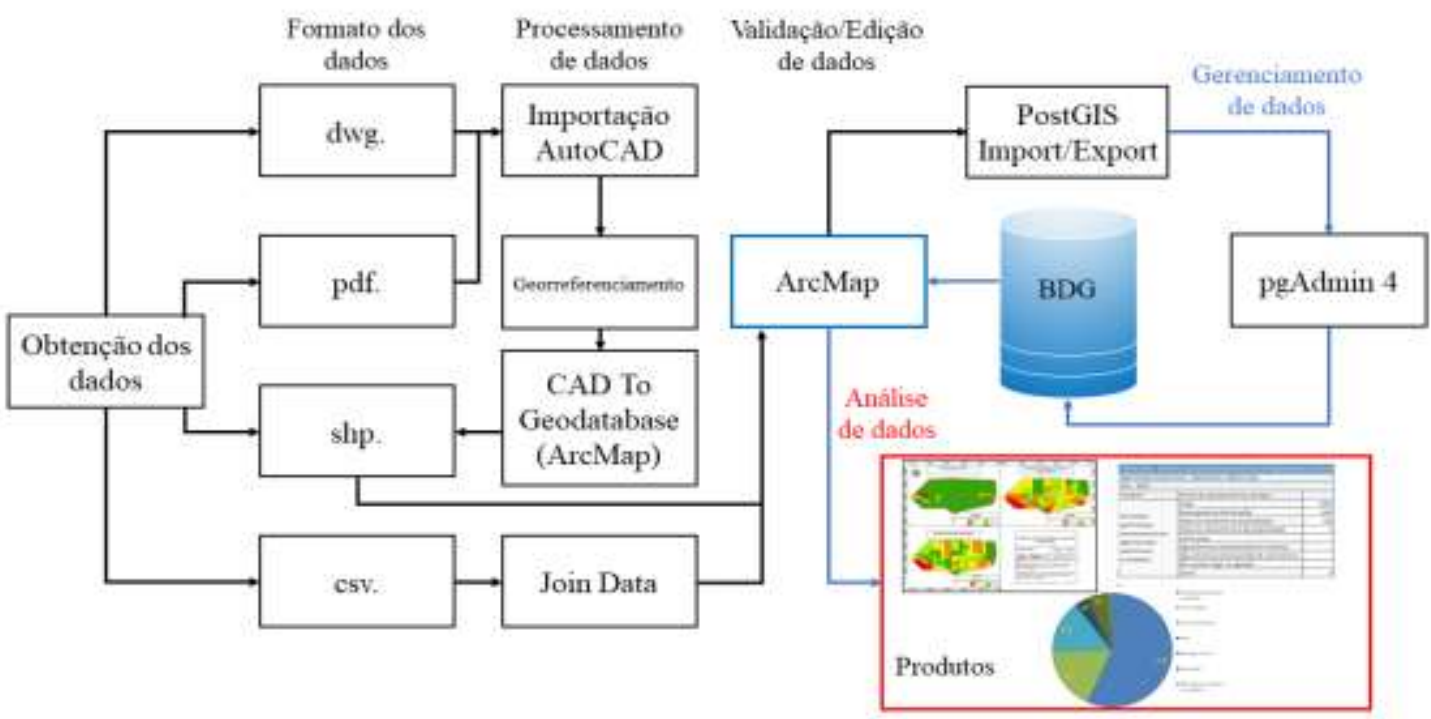

Fonte - Autores (2019).

\section{Banco de Dados do Saneamento da Marambaia}

No comando SQL executado no pgAdmin 4 para criação do BD (Figura 3), utilizou-se a codificação em ENCODING 'UTF-8' com padrão de grafia 'Portuguese_Brazil.1252' para a ordem de cadeia dos caracteres em LC_COLLATE e para a classificação de caracteres em LC_CTYPE, nos demais se utilizaram o padrão do PostgreSQL. Estes comandos devem ser fixos e padronizados para não corromper o texto das tabelas que serão adicionados ou criados.

Figura 3 - Script de criação do banco de dados, 2019.

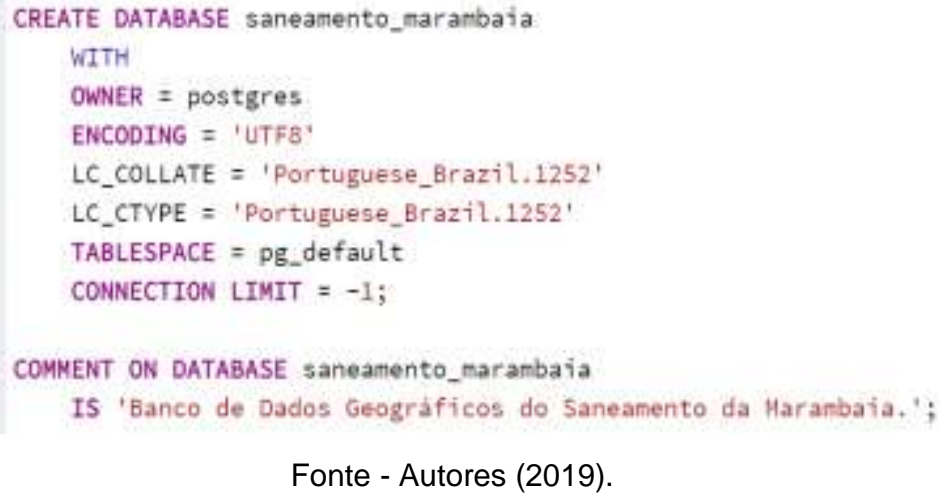

Em seguida, criou-se a extensão postgis que auxiliará na importação e leitura dos arquivos shapefiles georreferenciados para 0 banco de dados. Os Esquemas public e topology são criados

$\begin{array}{lllll}\text { Caminhos de Geografia } & \text { Uberlândia-MG } & \text { v. 22, n. } 83 & \text { out./2021 } & \text { p. 86-103 }\end{array}$


automaticamente pelo programa pgAdmin 4, nele é possível criar tabelas por meio dos scripts ou importar arquivos shapefiles através do módulo geográfico PostGIS Shapefile Import/Export Manager, indicando sua projeção Spatial Reference System Identifier (SRID) e o nome atribuído a tabela. Antes disso, cria-se uma conexão com o banco pelo PostGIS connection como demonstra a Figura 4.

Figura 4 - Conexão do PostGIS com o banco de dados, 2019.

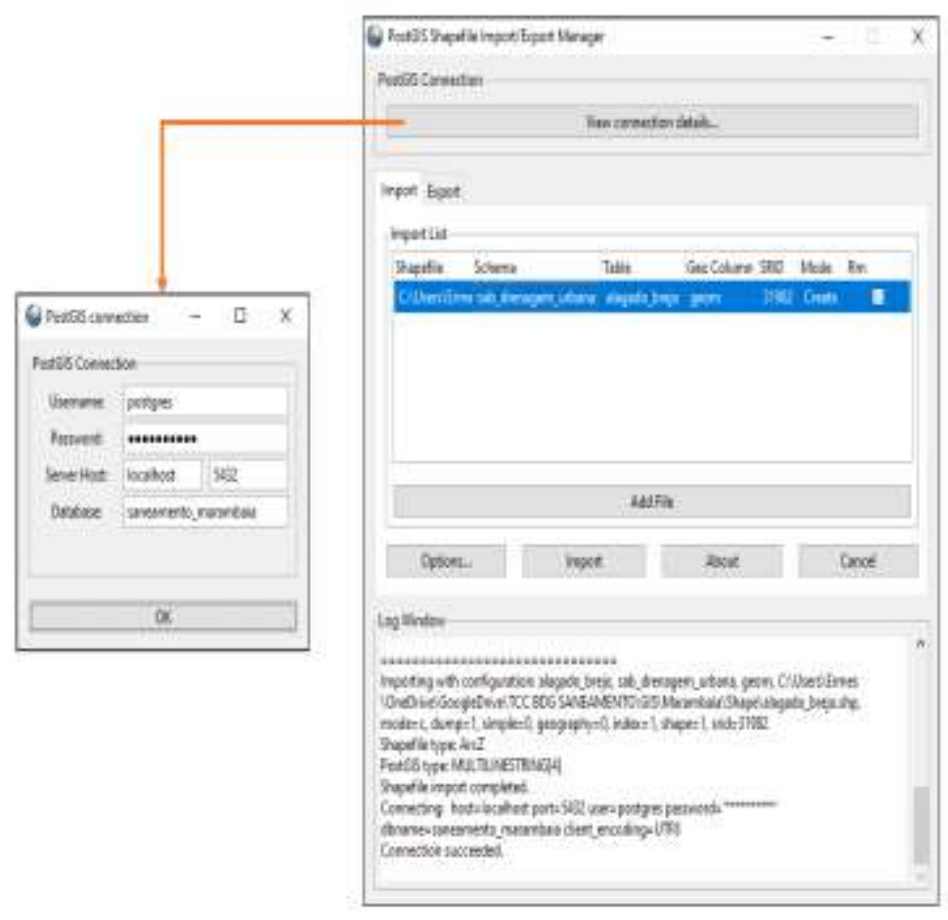

Fonte - Autores (2019).

Com todos os dados importados para o banco 'saneamento marambaia', os mesmos puderam ser manipulados e gerenciados no pgAdmin 4 e integrados aos conjuntos de programas de geoprocessamento como Quantum GIS 3 (QGIS 3) e ArcGIS 10.5.1. Diferente do ArcGIS, o QGIS apresenta sua plataforma com fácil integração ao PostgreSQL, sendo uma ótima alternativa, devido sua licença open source., no entanto, utilizou-se o ArcGIS 10.5 devido seu alto poder de processamento, a familiarização com o programa e a disponibilidade da licença pela Universidade do Estado do Pará (UEPA).

\section{RESULTADOS E DISCUSSÕES}

A partir do BDG "saneamento_marambaia" gerou-se tabelas e mapas ilustrando a situação do saneamento básico na Marambaia. No pgAdmin 4, os dados foram organizados em esquemas ou categorias (schemas) criados para tornar os objetos do BDG mais gerenciáveis e em grupos lógicos, favorecendo o uso por múltiplos usuários, apresentado na Figura 5. Estes foram criados de acordo com as recomendações da Comissão Nacional de Cartografia (CONCAR) por meio das Especificações Técnicas para Estruturação de Dados Geoespaciais Vetoriais ET - EDGV que regulamenta a estruturação de dados espaciais (CONCAR, 2017).

Caminhos de Geografia Uberlândia-MG v. 22, n. $83 \quad$ out./2021 p. 86-103 Página 91


Figura 5 - Interface gráfica do banco de dados, 2019.

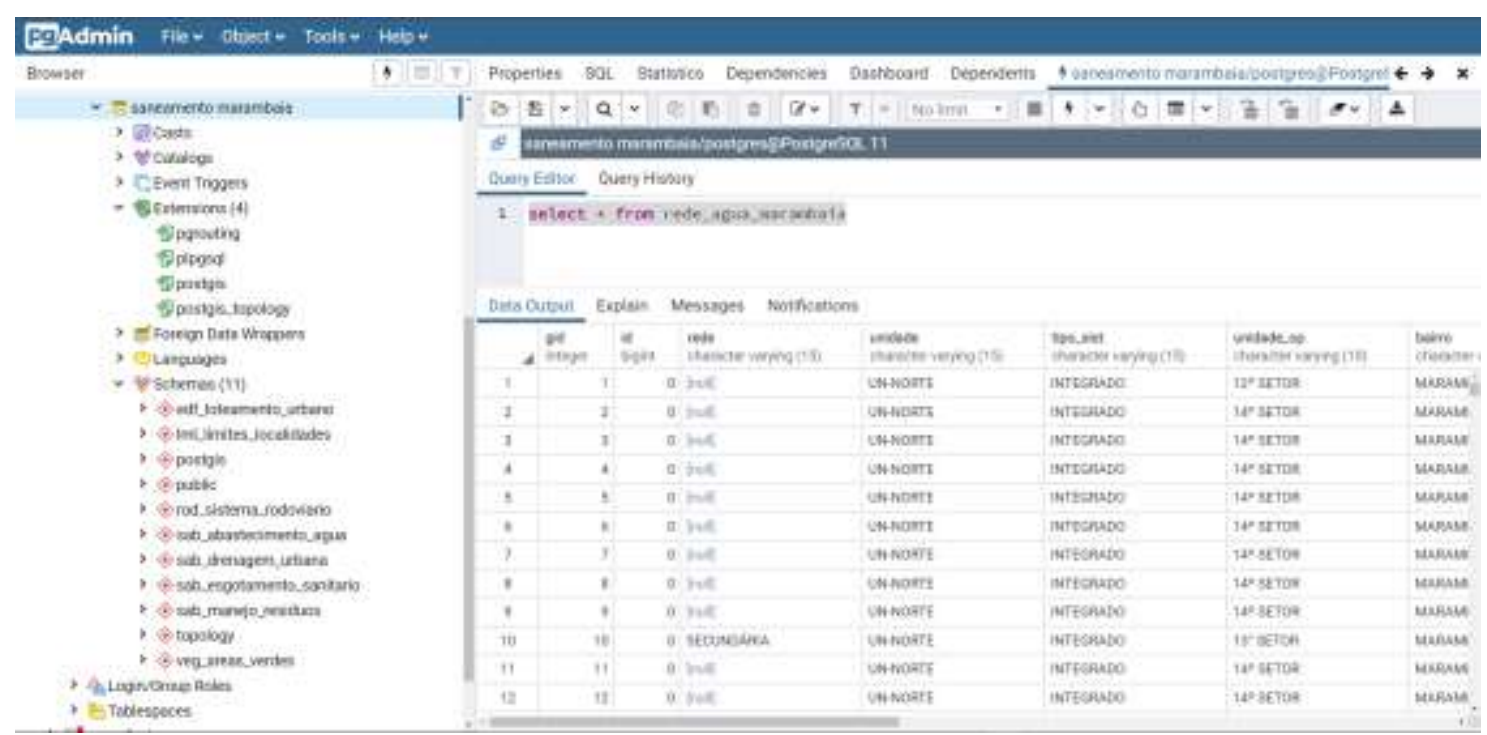

Fonte - pgAdmin 4 (2019).

\section{Ordenamento Territorial e Áreas Protegidas}

A Figura 6 a seguir demonstra a urbanização do bairro, a divisão de lotes, quadras e os logradouros. Estas informações são importantes para o cadastro de domicílios e usuários dos serviços de saneamento, além de auxiliar na logística e quantificação da demanda pelos serviços.

Figura 6 - Marambaia (Belém-PA): Loteamento urbano, 2019.

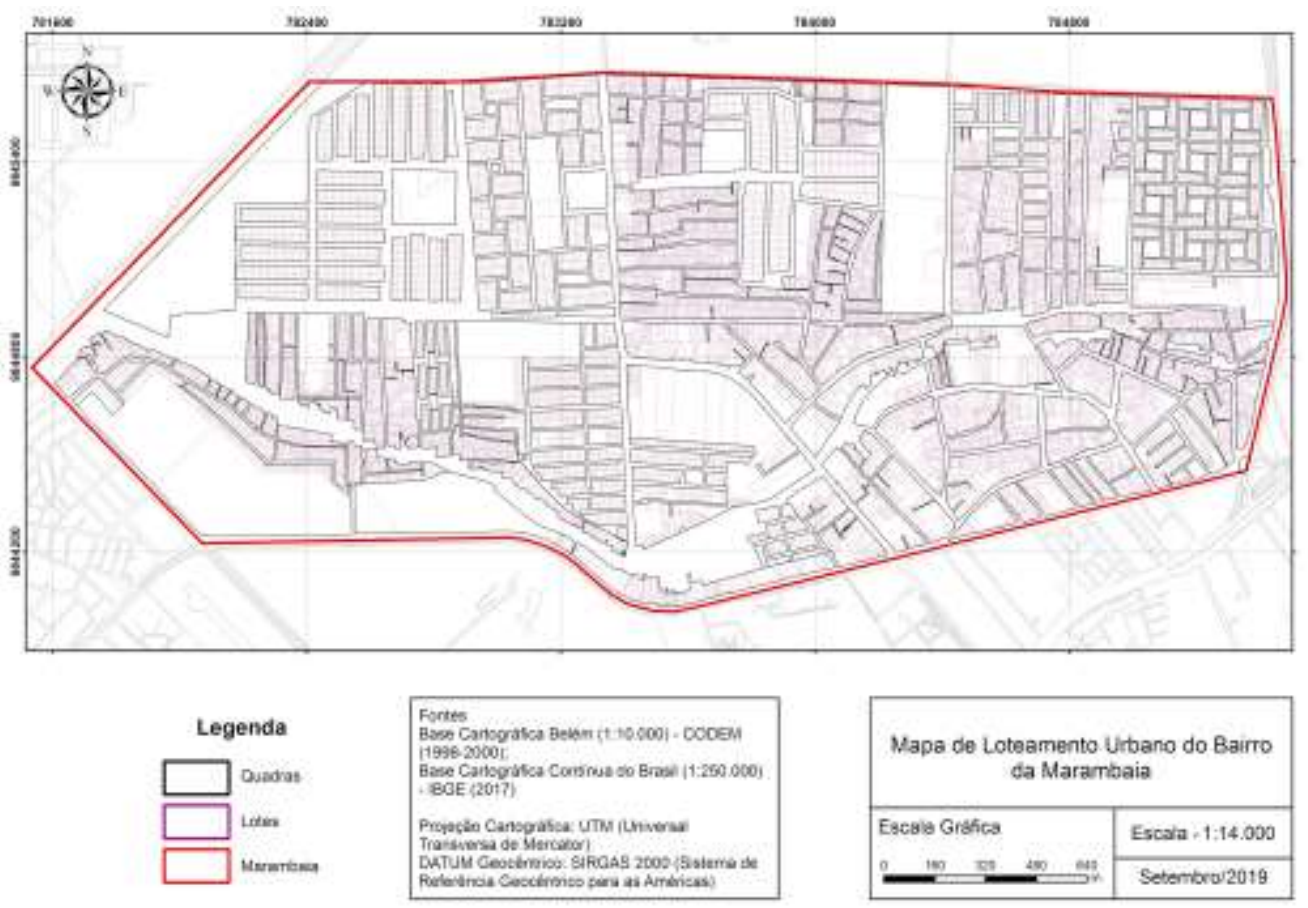

Fonte - Autores (2019).

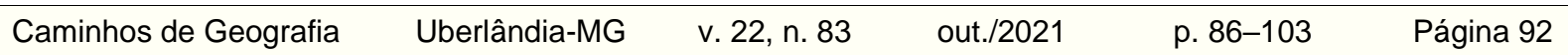


O crescimento populacional do bairro da Marambaia teve aumento de 7\% conforme dados do Censo do IBGE de 2000 e 2010 contabilizando 62.370 e 66.708 respectivamente (IBGE 2002; IBGE 2012). Esta variação é influenciada pela Avenida Augusto Montenegro que tange o limite nordeste do bairro, onde há concentração de novos empreendimentos imobiliários e serviços, ao longo de sua extensão. A Figura 7 a seguir revela a densidade demográfica por setor censitário e a delimitação dos principais conjuntos habitacionais do bairro.

Figura 7 - Marambaia (Belém-PA): Densidade Demográfica e Conjuntos habitacionais, 2019.
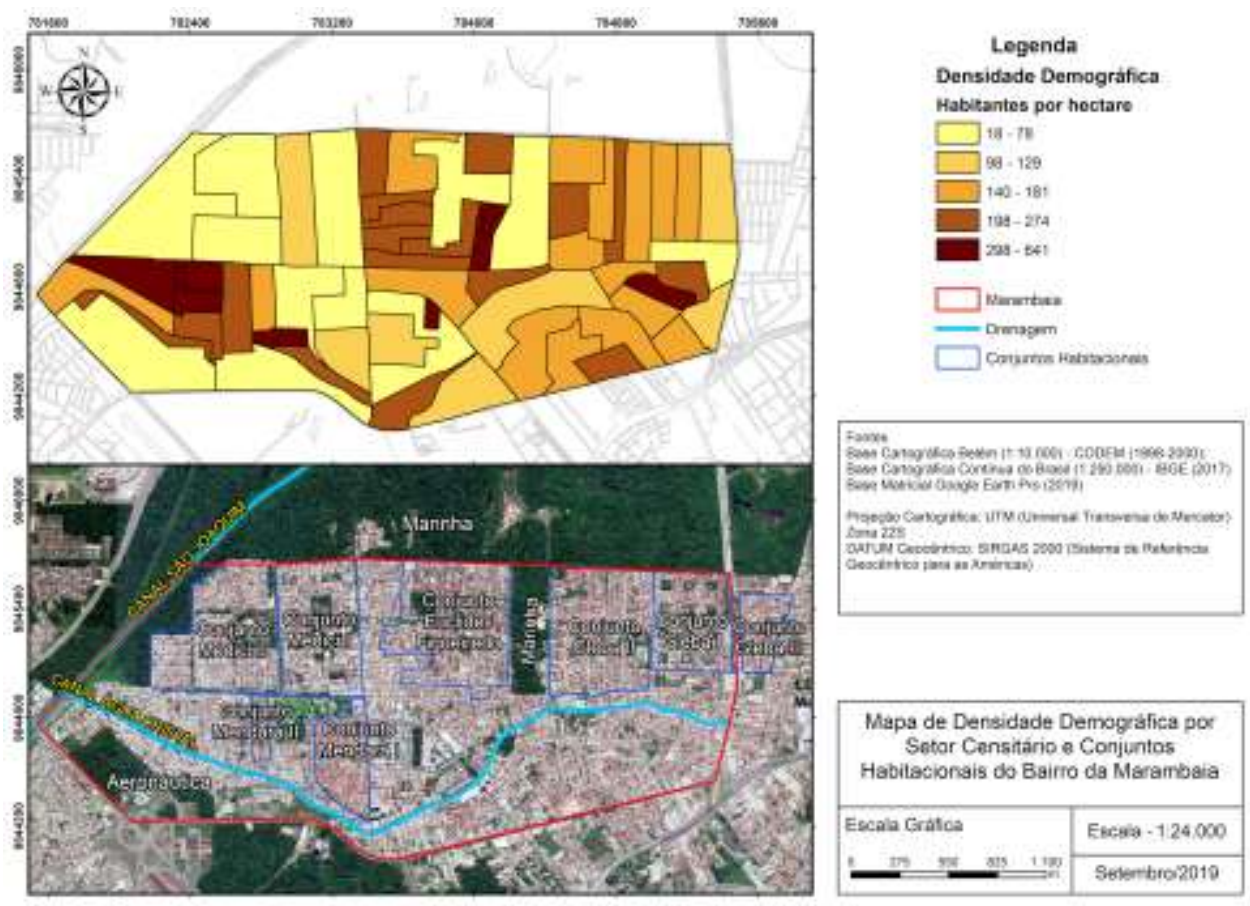

Fonte - Autores (2019).

Os conjuntos habitacionais existentes no bairro são outro fator que explica seu processo de urbanização e ocupação. Entre os principais conjuntos estão o Gleba I e o Gleba II da Companhia de Habitação do Estado do Pará (COHAB) e os conjuntos Médici I e II, que se caracterizam pela horizontalidade e planejamento de serviços de infraestrutura, portanto, apresentam uma ocupação regular e densidade demográfica de até 181 habitantes por hectare. Apesar de estar fora dos limites do bairro, o Gleba III tem forte influência na dinâmica populacional da Marambaia. As maiores densidades demográficas apresentada pela Figura 7 concentram-se ao longo do Canal Água Cristal e ao entorno dos conjuntos. Existe ainda no bairro duas áreas, uma pertencente à Marinha do Brasil localizada entre os Conjuntos Gleba II e Euclides Figueiredo e outra de domínio da Aeronáutica, logo estas apresentam baixa densidade demográfica.

Conforme o Plano Diretor de Belém (2008), o bairro da Marambaia encontra-se na Macrozona do Ambiente Urbano (MZAU), correspondente às áreas urbanas consolidadas e ainda está inserida na Zona do Ambiente Urbano 4 (ZAU 4), que se caracteriza por uso predominantemente residencial, atividades econômicas dispersas, presença de núcleos industriais, carência de equipamentos públicos e infraestrutura não consolidada. Outra parcela encontra-se na ZAU 6 - Setor III, correspondendo à presença de núcleos comerciais, com alta atratividade e forte tendência ao adensamento, com infraestrutura e equipamentos públicos escassos. A Figura 8 ilustra estas zonas e as áreas verdes presentes no bairro.

Caminhos de Geografia Uberlândia-MG v. 22, n. $83 \quad$ out./2021 p. 86-103 Página 93


Figura 8 - Marambaia (Belém-PA): Ordenamento territorial e áreas protegidas, 2019.

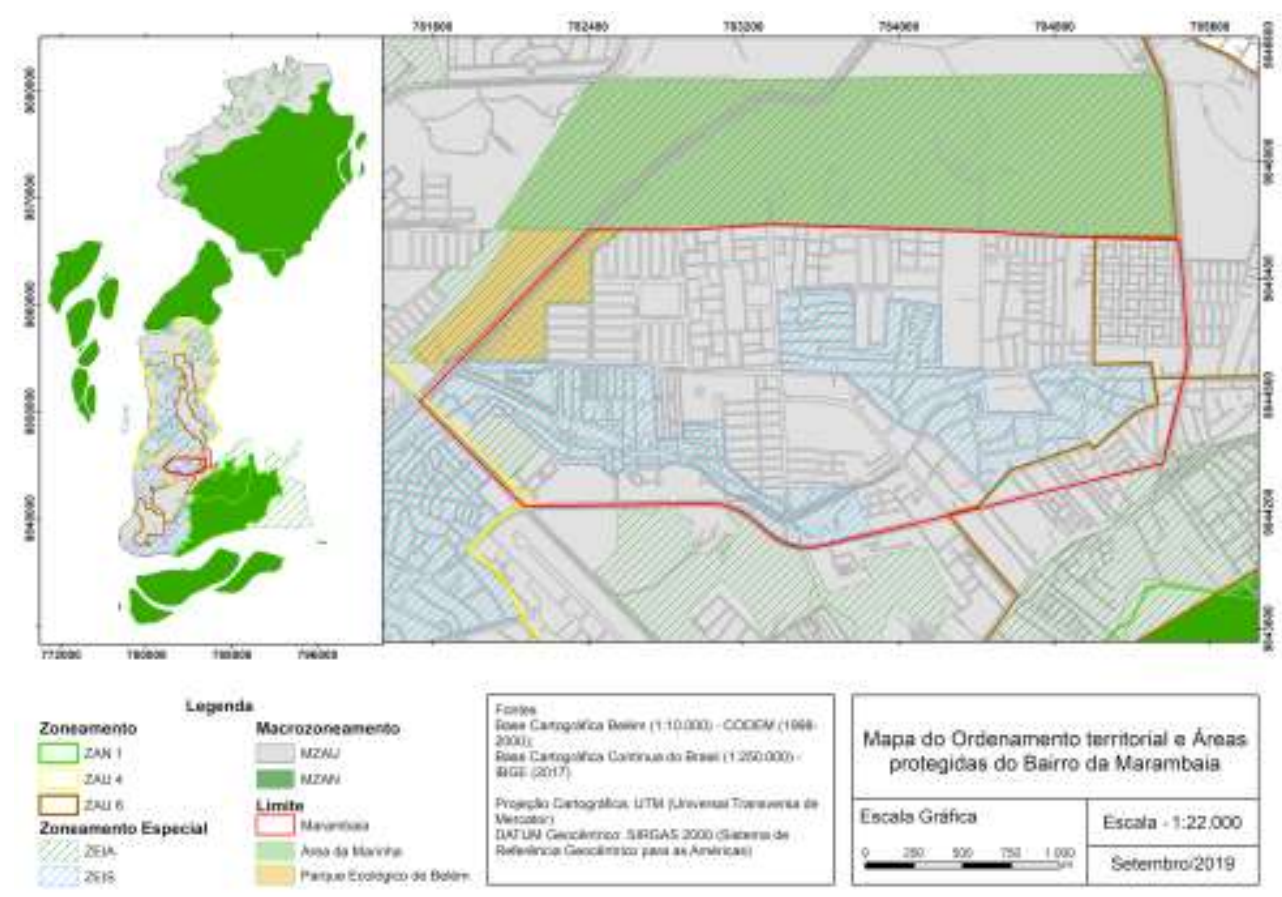

Fonte - Autores (2019).

Outras delimitações que não englobam o bairro, mas são de importância municipal referem-se a Zona do Ambiente Natural 1 (ZAN 1) que abriga os mananciais Lago Bolonha e Lago Água Preta responsáveis pelo abastecimento de água do município, assim como a Macrozona do Ambiente Natural (MZAN) que também abrange as ilhas municipais de Belém. Ainda entre as áreas verdes da Marambaia, segundo a Figura 8, encontra-se o Parque Ecológico do Município de Belém Gunnar Vingren que é uma Área de Proteção Ambiental (APA), criado pela lei municipal de n.․․ 7.539 de 19 de novembro de 1991, com 44 hectares, localizado nos bairros da Marambaia e Val de Cans, o mesmo é administrado pela SEMMA. O bairro ainda faz divisa com a Área da Marinha, considerada no Plano Diretor de Belém como Zona Especial de Interesse Ambiental (ZEIA), a qual constitui áreas importantes para a manutenção do equilíbrio socioambiental. Além dessas, uma porção do território faz parte da categoria: Zonas Especiais de Interesse Social (ZEIS), cuja área recebe tratamento diferenciado, para viabilizar ações de urbanização, regularização fundiária e habitação, motivando a permanência da população local (BELÉM, 2008, p. 45-73). Estas áreas contribuem com a qualidade ambiental urbana e servem de proteção para diversas nascentes e também para os cursos d'água que cortam estas áreas, portanto, constituindo-se uma camada de informações relevante para a estruturação do BDG.

\section{Cobertura do Saneamento Básico}

Conforme a Figura 9, o bairro da Marambaia apresenta sessenta setores censitários e uma excelente cobertura de coleta de resíduos sólidos domiciliares entre $97 \%$ a $100 \%$, enquanto em relação ao abastecimento de água via rede geral o percentual é de 7\% a 40\% em apenas dois setores censitários, revelando um déficit deste serviço nestas áreas, porém o setor na cor vermelha encontra-se uma instituição de ensino de grande porte e em laranja a área da Aeronáutica, o que explica a baixa taxa de cobertura dos domicílios atendidos por este serviço, visto que esta área dispõe de baixa densidade demográfica. E em outros doze setores o percentual é de $56 \%$ a $60 \%$ apresentando boa cobertura, o restante alterna entre $69 \%$ a $100 \%$ dos domicílios atendidos pela rede geral em quarenta e seis setores censitários, caracterizando ótima ou excelente cobertura. O esgotamento sanitário via rede geral de esgoto ou pluvial, apresenta baixos índices de cobertura na região sudoeste, não obstante, o conjunto

$\begin{array}{lllll}\text { Caminhos de Geografia } & \text { Uberlândia-MG } & \text { v. 22, n. } 83 & \text { out./2021 } & \text { p. 86-103 }\end{array}$


Gleba I e Médici I apresentam $81 \%$ a $100 \%$ dos domicílios atendidos, além disso, a maior parte dos conjuntos estão entre boa e excelente taxa de cobertura. Em outros quinze setores censitários equivalentes a uma área de 1,34 $\mathrm{km}^{2}$, a cobertura está entre $6 \%$ a $40 \%$ mostrando um déficit deste serviço como ruim ou péssima cobertura.

Figura 9 - Marambaia (Belém-PA): Cobertura do saneamento dos setores censitários por domicílios permanentes, 2019.

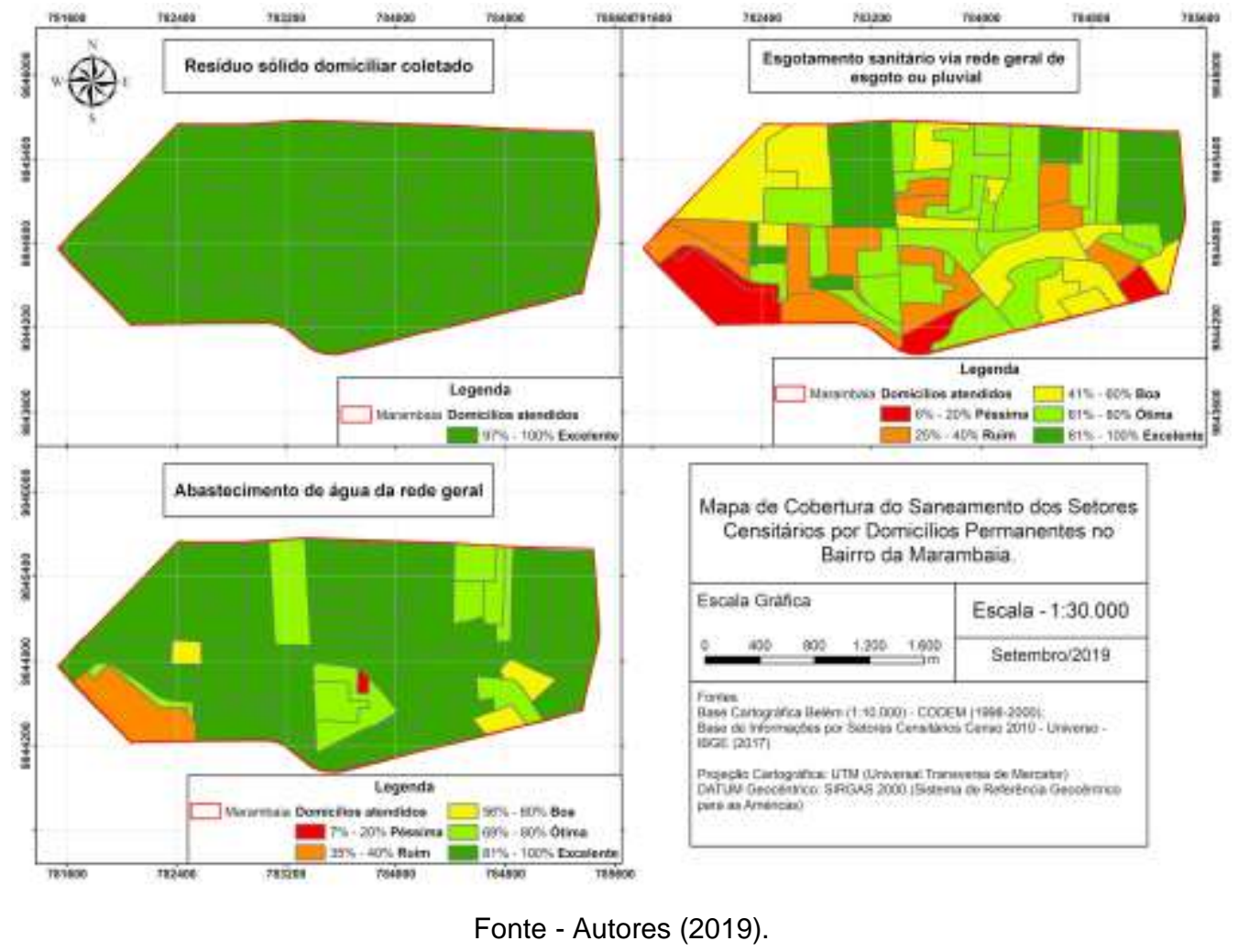

Em relação aos dados de pluviais, o IBGE os classifica junto aos de esgoto, considerando casos de irregularidades onde se tem a ligação clandestina da tubulação de esgoto domiciliar à rede de drenagem pluvial. A análise dos dados da Figura 9 facilita a gestão e o planejamento de ações integradas do saneamento básico, pois permite identificar quais setores censitários estão com maiores déficits e onde priorizar 0 atendimento dos serviços. A espacialização dessas informações pode ser mais detalhada englobando outras variáveis, o que irá facilitar a identificação das áreas por setor censitário. Com isso, o direcionamento das políticas públicas e os investimentos na área podem ser aplicados efetivamente visando sua universalização.

\section{Hidrografia e Drenagem Urbana}

A Região Metropolitana de Belém (RMB) é recortada por 14 bacias hidrográficas, sendo que a maior é a Bacia do Una com $39,53 \mathrm{~km}^{2}$, na qual se localiza o bairro da Marambaia que é cortado pelo canal Água Cristal, afluente do canal São Joaquim, o maior canal urbano de Belém em extensão com 11,25 km como exibe na Figura 10. O canal Água Cristal é o principal condutor de efluentes domésticos e pluviais da Marambaia, junto ao canal São Joaquim que faz a condução final e o despejo na Baía do Guajará (BELÉM, 2019).

$\begin{array}{lllll}\text { Caminhos de Geografia } & \text { Uberlândia-MG } & \text { v. 22, n. } 83 & \text { out./2021 } & \text { p. 86-103 Página } 95\end{array}$


Figura 10 - Marambaia (Belém-PA): Rede de macrodrenagem da bacia do Una, 2019.

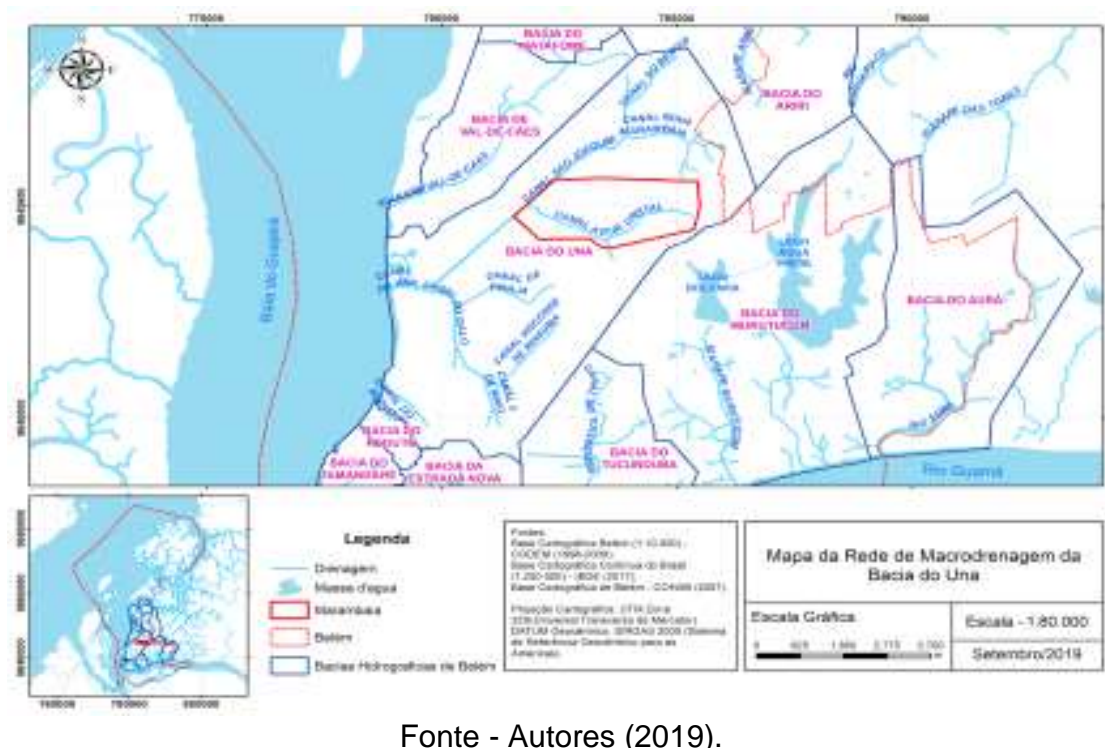

A água das chuvas drenada pela Bacia do Una, onde habitam cerca de 400.000 pessoas e que ocupa $60 \%$ do sítio urbano de Belém, contribuem com 19\% das áreas alagáveis e sujeitas à influência das marés (CRUZ e SOARES, 2019). Os alagamentos em Belém caracterizam-se de acordo com o nível máximo de maré, possuindo uma cota de alagamento de 3,70 metros acima do nível do mar (SILVA, 2001).

De modo a reduzir as áreas alagáveis na $\mathrm{RMB}$, os canais naturais foram retificados, como também a instalação de comportas, impedindo o retorno das águas da Baía do Guajará nos períodos de maré alta, como é o caso da comporta localizada na foz do canal São Joaquim que também interfere no regime de escoamento do canal Água Cristal, protegendo os terrenos baixos (COSANPA, 2019). A Figura 11 elucida a drenagem urbana no bairro.

Figura 11 - Marambaia (Belém-PA): Drenagem urbana, 2019.

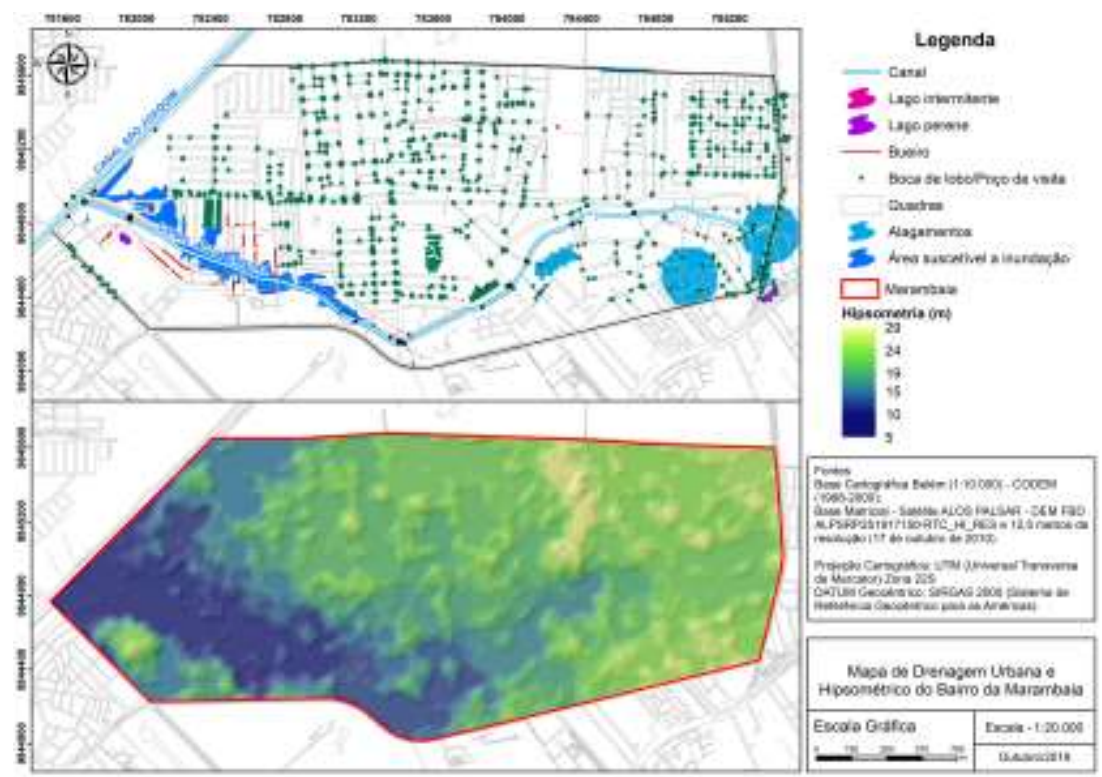

Fonte - Autores (2019). 
A análise espacial da Figura 11 revela que as áreas de inundação do bairro da Marambaia não sobrepõem às de alagamento, estas se concentram em locais topograficamente altos, mostrando que a causa destas se deve a outros fatores, como entupimento de bueiros e galerias, e a falta de manutenção da rede de drenagem não sendo, portanto, influenciado pelo nível da maré. Apesar da excelente cobertura de coleta de resíduos no bairro, ocorrem casos pontuais de disposição inadequada de resíduos sólidos nos canais Água Cristal e São Joaquim, sendo outro fator que agrava o problema de escoamento das águas, prejudica a qualidade do curso d'água, podendo nos períodos de cheias facilitar a proliferação de doenças. O mapeamento de áreas alagáveis por meio do SIG junto à sobreposição de dados hidrográficos se torna uma importante ferramenta que auxilia a operação e manutenção da rede de drenagem pluvial no bairro da Marambaia.

A partir do conhecimento das informações hidrográficas, climáticas, topográficas e geomorfológicas, e da disponibilidade em um único BDG facilita o planejamento e gestão do sistema de drenagem urbana, visto que estas informações interferem diretamente no escoamento superficial e na infiltração de águas pluviais subsidiando o dimensionamento do sistema de drenagem urbana e a prevenção e monitoramento de alagamentos.

\section{Sistema de Abastecimento de Água}

O bairro da Marambaia faz parte da Unidade de Negócio do Norte (UN-NORTE) e compõe o sistema integrado da COSANPA e os setores operacionais: $10 . \stackrel{\circ}{1} 12 . .^{\circ}, 13 . \circ$ e $14 . .^{\circ}$, os quais são abastecidos pela Estação de Tratamento de Água (ETA) Bolonha a qual realiza o tratamento da água oriunda do Rio Guamá e armazenada nos Lagos Água Preta e Bolonha (COSANPA, 2019). A rede presente nos limites do bairro possui uma extensão total de $114,20 \mathrm{~km}$ dividida em tubos de $\varnothing 50$ a $\varnothing 500 \mathrm{~mm}$, predominando o diâmetro de $\varnothing 50$ e $\varnothing 75 \mathrm{~mm}$ representando 59,72\%, e ainda, possui 14 reservatórios conforme ilustra a Figura 12. A espacialização da tubulação de abastecimento de água por diâmetro favorece a visualização, demarcação, consulta e a manutenção da rede.

Figura 12 - Marambaia (Belém-PA): Sistema de abastecimento de água por Material e Diâmetro Nominal (DN), 2019.
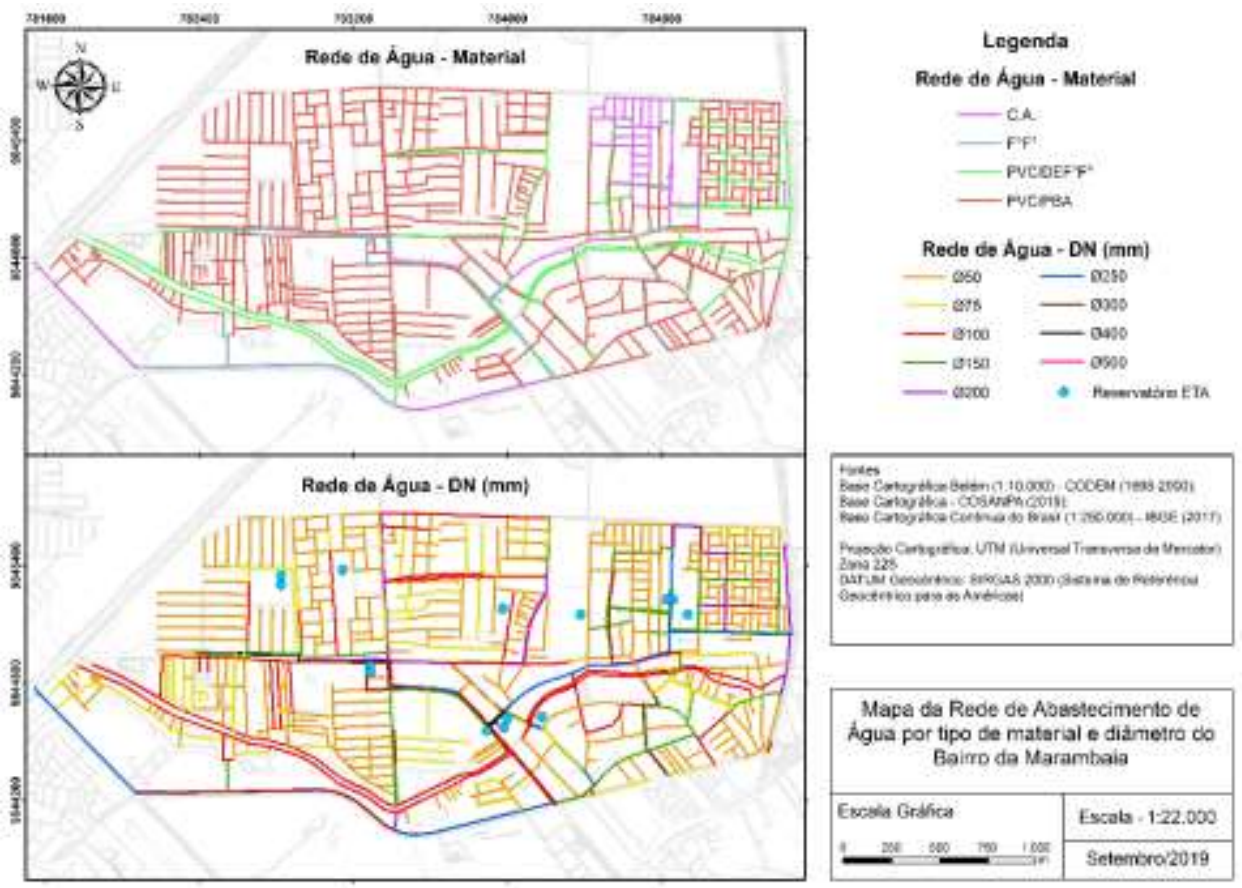

Fonte - Autores (2019).

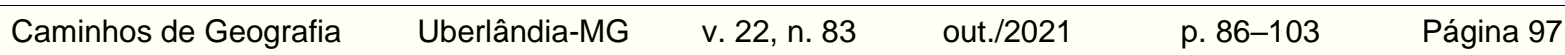


Em relação ao material, observa-se na Figura 12 o predomínio do tipo polivinila de cloreto de ponta bolsa com anel de borracha (PVC/PBA) correspondendo a 66,39\%. A tubulação que contorna o canal Água Cristal é do tipo polivinila de cloreto modificado com diâmetro de tubos de ferro fundido (PVC/DEFoFo) de alta resistência a impacto e ideal para sistemas enterrados de abastecimento de água. Com relação às tubulações de Ferro Fundido Dúctil (FoFo) apresenta utilização em pequenos trechos e esse material encontra-se em desuso devido aos riscos de contaminação da água o qual indicava. Sobre o material de Cimento Amianto (CA) também exibiu baixo emprego, pois sua produção é altamente contaminante podendo em pequenas quantidades apresentar risco de tumores e desenvolvimento de câncer para aqueles que têm contato. Outra questão diz respeito ao fato de que o emprego de tal tubulação é de aplicação antiga, quando não se tinha a preocupação com a toxicidade do amianto, nem tampouco a vasta disponibilidade de tubulações de PVC, além do que o material não é reciclável e que produtos com o amianto, não podem ser descartados inadequadamente (CONAMA, 2004).

\section{Sistema de Esgotamento Sanitário}

Em 1983 iniciou-se o Programa de Ação Social em Saneamento (PROSEGE) com a implantação de sistemas de esgotamento sanitário abrangendo os bairros da Marambaia e Guanabara. O programa, finalizado em 2001, obteve financiamento do Banco Internacional para Reconstrução e Desenvolvimento (BIRD), da Caixa Econômica Federal (CEF) e do Governo do Estado do Pará (PMSB I, 2014). O sistema de esgotamento sanitário e o diâmetro estão representados na Figura 13.

Figura 13 - Marambaia (Belém-PA): Sistema de esgotamento sanitário por Diâmetro Nominal (DN), 2019.

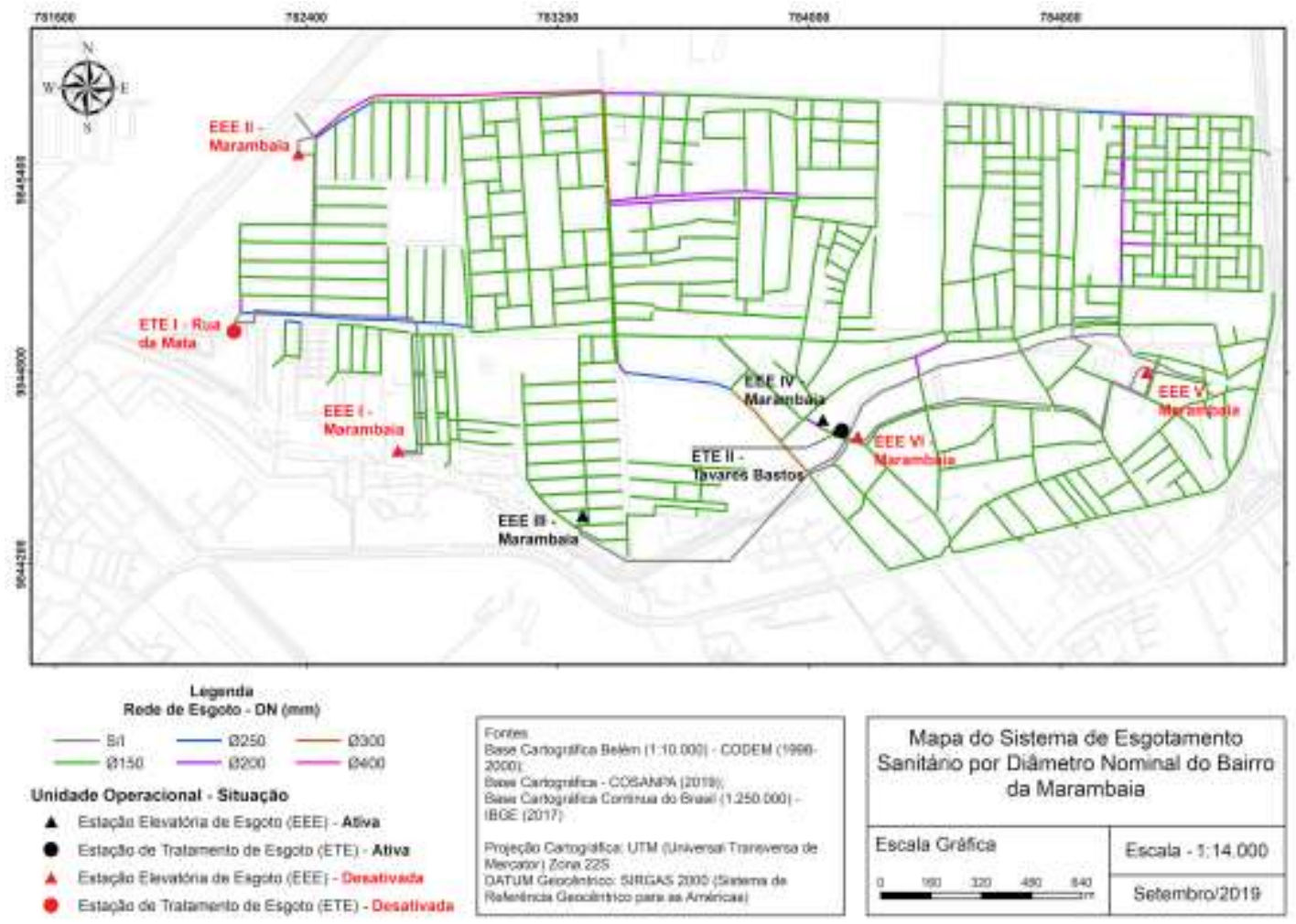

Fonte - Autores (2019). 
Como demonstrado na Figura 13, o diâmetro da tubulação de esgoto varia de $\varnothing 150$ a $\varnothing 400$ mm, sendo que predomina o de $\varnothing 150 \mathrm{~mm}$. O bairro apresenta duas Estações de Tratamento de Esgoto (ETE) e seis Estações Elevatórias de Esgoto (EEE), porém apenas a ETE II Tavares Bastos está funcionando, além das EEE's III e IV, portanto, os efluentes das residências a noroeste e sudoeste do bairro não estão sendo tratados pela ETE I Rua da Mata e de acordo com o PMSB I (2014) a sua capacidade de tratamento instalada era da ordem de $82 \mathrm{~L} / \mathrm{s}$ na fase 1 existente, passando para 97,0 L/s na segunda fase (a ser implantada). O efluente tratado era lançado no Canal Água Cristal, mas por motivos de depredação e saques, a ETE encontra-se totalmente desativada.

A ETE II Tavares Bastos apresenta unidade de gradeamento, estação elevatória de esgoto, unidade de desarenação, reatores anaeróbios de manta de lodo, tanque de mistura rápida, unidade de floculação, sistema de flotação, sistemas de tratamento de biogás, sistema de desaguamento de lodo e desinfecção. A ETE apresenta uma capacidade nominal de tratamento de $230,0 \mathrm{~L} / \mathrm{s}$ e possui como dispositivo de medição de vazão e misturas rápidas a Calha Parshall na elevação bruta.

Segundo informações da administração da ETE II Tavares Bastos, o material da tubulação do SES da Marambaia é de PVC na área do atual PROSEGE, e C.A. na parte sudoeste do bairro e a nordeste nos conjuntos habitacionais da COHAB (Gleba 1 e 2) como exibe a Figura 14. O PVC Vinilfort é ideal para transporte de esgoto sanitário em redes coletoras, além disso, possui alto desempenho hidráulico e resistência mecânica, já os recalques são de FoFo, pois apresentam resistência mecânica, à compressão, à dilatação térmica, estabilidade estrutural e alta ductilidade.

Figura 14 - Marambaia (Belém-PA): Rede de esgotamento sanitário por tipo material, 2019.
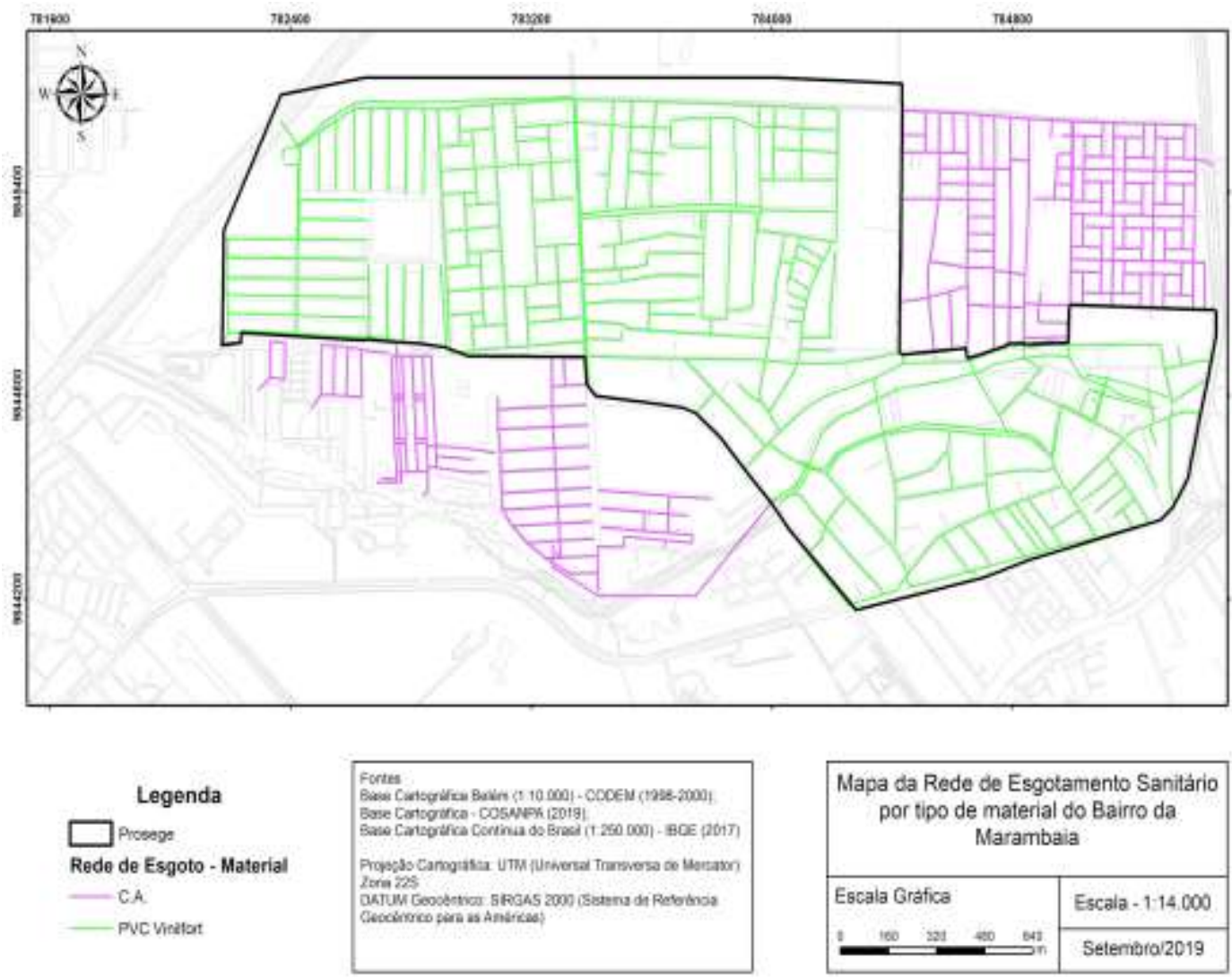

Fonte - Autores (2019).

$\begin{array}{lllll}\text { Caminhos de Geografia } & \text { Uberlândia-MG } & \text { v. 22, n. } 83 & \text { out./2021 } & \text { p. 86-103 }\end{array}$




\section{Resíduos Sólidos Domiciliares}

No que concerne ao manejo de Resíduos Sólidos Domiciliares (RDO) do bairro da Marambaia, a BA Meio Ambiente Ltda. realiza 6 roteiros, feito em 2 viagens, 3 vezes por semana no período noturno, em média totalizando na terça-feira: 81,580 ton., na quinta-feira: 55,130 ton. e no sábado: 57,830 ton. Com isto, a média da massa de RDO coletada per capita em relação à população total atendida chega a $0,97 \mathrm{~kg} / \mathrm{hab}$.dia, maior que a média nacional e municipal de Belém de 0,69 kg/hab.dia conforme os dados do Diagnóstico do Manejo de Resíduos Sólidos Urbanos do SNIS (2019). Os roteiros são feitos de forma alternada para otimizar os custos com mão de obra e equipamentos. Não foi possível espacializar os roteiros devido à falta de acesso aos dados espaciais.

A respeito da coleta seletiva de resíduos recicláveis, esta é realizada por meio de carrinho de mão tipo gaiola, porta-a-porta e armazenada em bags nas esquinas com parceria de associações de catadores, como a Associação de Reciclagem das Águas Lindas (ARAL) e a Associação de Catadores da Coleta Seletiva de Belém (ACCBS).

O roteiro de coleta executado pela ARAL e a localização do Ponto de Entrega Voluntária (PEV) de resíduos recicláveis, que contribui para o acondicionamento e recolha destes, na praça Dom Alberto Ramos, são exibidos pela Figura 15.

Figura 15 - Marambaia (Belém-PA): Rota de Coleta Seletiva da ARAL, 2019.
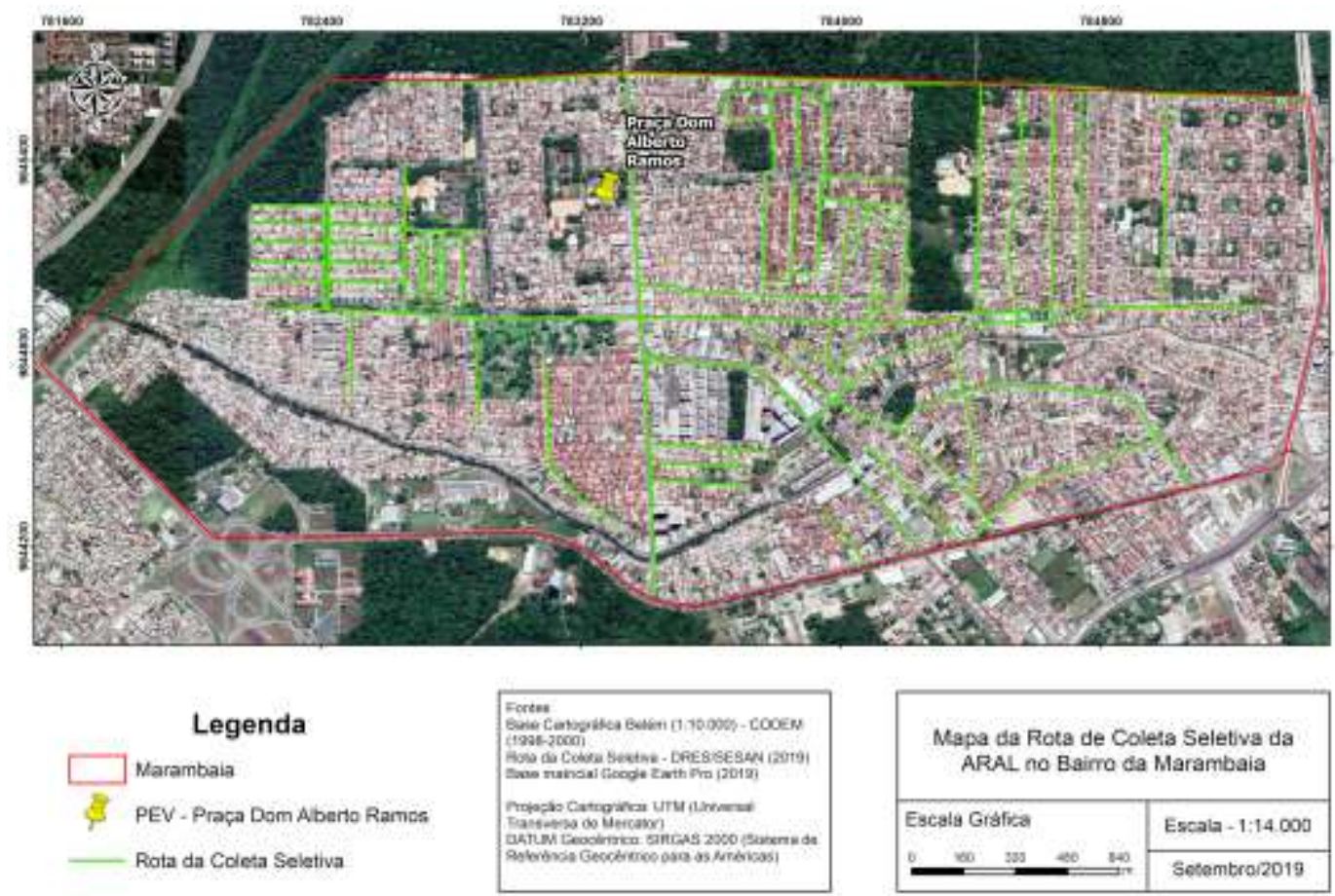

Fonte - Adaptado da SESAN (2019).

A ACCBS efetua a coleta em um grande gerador de resíduos: Mariny Alimentos Comércio e Indústria, localizada na Rua São Jorge 146, com periodicidade de uma vez por semana.

Foi acrescentada também no BDG a Tabela 1 que representa a roteirização de coleta feita pela ARAL em logradouros e conjuntos habitacionais nas segundas e sextas-feiras.

$\begin{array}{lllll}\text { Caminhos de Geografia } & \text { Uberlândia-MG } & \text { v. 22, n. } 83 & \text { out./2021 } & \text { p. 86-103 }\end{array}$


Tabela 1 - Marambaia (Belém-PA): Roteirização da coleta de resíduos recicláveis, 2019.

\begin{tabular}{lllll}
\hline & Carlos Magno & São Francisco & Nova & José de Alencar \\
Passagens & Bem & Arama & Liberdade & São Raimundo \\
& Dalva & Aliados & São Vicente & Reis Teixeira \\
& Santa Helena & São Cristóvão & Iracema & Santa Rita \\
\hline \multirow{2}{*}{ Rodolfo Chermont } & Quinta & Anchieta & Canal \\
& Esperanto & Marinha & A/B/C/D/E/F/G/l/J/K/L & Quarta \\
& Mata & São Jorge & N. Sr. a de Fátima & Sexta \\
\hline Travessas & Sn 6 & & & \\
\hline Avenidas & Tavares Bastos & Dalva & A & \\
\hline Conjuntos & Médici II & Ypuan & Vitória Régia & \\
\hline
\end{tabular}

É de grande importância os dados a respeitos da frequência e roteirização de coleta do resíduo, pois a partir desses é possível avaliar a demanda e otimizar o processo, o que facilita no planejamento quanto à logística e operação do serviço, diminuindo custos e evitando acumulação de resíduos e ausência de coleta nas ruas, reduzindo assim riscos de doenças e pontos de alagamento no bairro, melhorando a saúde pública. Estudos sobre melhores rotas e frequências das coletas podem ser atualizados com frequência regular aliando estes dados aos demais dados do banco.

\section{CONSIDERAÇÕES FINAIS}

A aplicação do Banco de Dados Geográficos (BDG) para a gestão integrada do saneamento básico sistematizou as camadas de informações das características urbanas e ambientais do bairro da Marambaia, assim como viabilizou a integração e análise dos dados, atendendo ao objetivo deste trabalho e auxiliando futuras intervenções e propostas de melhorias pelos setores de planejamento e engenharia, através de bases de dados consistentes e integradas, assim como pelo acesso por múltiplos órgãos e instituições públicas ou privadas direcionando a formulação de políticas públicas condizentes com a realidade local.

Recomenda-se que a partir deste projeto-piloto o BDG possa ser expandido ao nível municipal aliado aos setores de habitação, saúde, economia e infraestrutura urbana, sendo possível interligá-los através de servidores e plataformas na web acessíveis à população e aos órgãos públicos, o que pode colaborar positivamente para a gestão integrada e tomada de decisões pautadas nas legislações vigentes.

\section{REFERÊNCIAS}

ALMEIDA, R. C. P.; BITENCOURT, W.; ARAÚJO, A. F.; RAMEH, I. M. B. Estruturação de um Banco de Dados Espacial como Repositório dos Dados do Projeto SIGAreias-ANE. CIENTEC-Revista de Ciência, Tecnologia e Humanidades do IFPE, v. 9, n. 3, 2017.

Caminhos de Geografia $\quad$ Uberlândia-MG $\quad$ v. 22, n. $83 \quad$ out./2021 $\quad$ p. 86-103 Página 101


BELÉM. Lei nº 8.655, de 30 de julho de 2008. Plano Diretor do Município de Belém. Belém: Câmara Municipal, p. 45-73, 2008. Disponível em:

http://www.belem.pa.gov.br/planodiretor/Plano_diretor_atual/Lei_N8655-08_plano_diretor.pdf. Acesso em: 9 jan. 2019.

BELÉM. Lei n. 7.539, de 19 de novembro de 1991. Cria o Parque Ecológico do Município de Belém. Belém: Câmara Municipal, p. 45-73, 1991. Disponível em: http://www.belem.pa.gov.br/pgm/home/wpcontent/uploads/2014/06/Legislacao-Meio-Ambiente-e-Urbanismo.pdf. Acesso em: 10 jan. 2019.

BELÉM. Prefeitura Municipal. Informações gerais sobre o município. Belém, 2019.

BELÉM. Prefeitura Municipal. Plano Municipal de Saneamento Básico de Abastecimento de Água e Esgotamento Sanitário do Município de Belém (PMSB) - Pará. v. I concepção técnica e proposições. Belém, 2014.

BELÉM. Prefeitura Municipal. Plano Municipal de Saneamento Básico de Abastecimento de Água e Esgotamento Sanitário do Município de Belém (PMSB) - Pará. v. Il concepção técnica e proposições. Belém, 2014.

BOSCARIOLI, C.; BEZERRA, A.; BENEDICTO, M. D.; DELMIRO, G. Uma reflexão sobre banco de dados orientados a objetos. In: Congresso de Tecnologias para Gestão de Dados e Metadados do Cone Sul, Paraná, Brasil. 2006. Disponível em: https://conged.deinfo.uepg.br/artigo4.pdf. Acesso em: 9 jun. 2019.

BRASIL. Ministério do Desenvolvimento Regional. Secretaria Nacional de Saneamento - SNS. Sistema Nacional de Informações sobre Saneamento (SNIS): Diagnóstico do Manejo de Resíduos Sólidos Urbanos - 2018. Brasília: SNS/MDR, 2019. 247 p. : il.

BRASIL. Lei $n^{\circ} 11.445$ de 05 de janeiro de 2007. Estabelece diretrizes nacionais para o saneamento básico. Diário Oficial da União. In: Brasília, DF, 05 jan. 2007. Disponível em: http://www.planalto.gov.br/ccivil_03/_ato2007-2010/2007/lei/l11445.htm. Acesso em: 9 jul. 2019.

COMISSÃO NACIONAL DE CARTOGRAFIA - CONCAR (Brasil). Especificações Técnicas para a Estruturação de Dados Geoespaciais Vetoriais - ET-EDGV. V. 3.0, dezembro de 2017. Disponível em: http://www.geoportal.eb.mil.br/portal/index.php/inde2?id=139. Acesso em: 23 set. 2019.

COMPANHIA DE SANEAMENTO DO PARÁ - COSANPA. Informações gerais sobre o Projeto Una. Belém, 2019.

CONSELHO NACIONAL DO MEIO AMBIENTE - CONAMA (Brasil). Resolução n 348 de 16 de agosto de 2004. Altera a Resolução n' 307, de 5 de julho de 2002, incluindo o amianto na classe de resíduos perigosos. Diário Oficial da União: n. 158, de 17 de agosto de 2004, Seção 1, página 70. Ministério do Meio Ambiente.

CRUZ, S. H. R; SOARES, P. P. M. A. A ecologia política das inundações urbanas na Bacia do Una em Belém (PA) (The political ecology of urban flooding in the Una Watershed in Belém, state of Pará). Emancipação, v. 19, n. 1, p. 1-15, 2019. Disponível em: https://revistas.apps.uepg.br/index.php/emancipacao/article/view/10947. Acesso em: 16 set. 2019. https://doi.org/10.5212/Emancipacao.v.19.0005

GUimarÃEs, R. J. P. S; RABElo, T; CATETE, C. P; ALVES, P. P. A; SILVA, R. C. Georreferenciamento dos pontos de alagamento em Belém (PA). In: CONGRESSO DA ABES/FENASAN, 2017. São Paulo. Saneamento Ambiental: desenvolvimento e qualidade de vida na retomada do crescimento. São Paulo: ABES/AESabesp, 2017. Disponível em:

https://www.tratamentodeagua.com.br/wp-content/uploads/2018/03/IX-103.pdf. Acesso em: 14 mai. 2019.

HELLER, L.; LISBOA, S. S.; SILVEIRA, Rogério Braga. Desafios do planejamento municipal de saneamento básico em municípios de pequeno porte: a percepção dos gestores. Engenharia Sanitária e Ambiental, v. 18, n. 4, p. 341-348, 2013. Disponível em: http://www.scielo.br/pdf/esa/v18n4/1413-4152-esa-18-04-00341.pdf. Acesso em: 7 nov. 2019. https://doi.org/10.1590/S1413-41522013000400006

$\begin{array}{lllll}\text { Caminhos de Geografia } \quad \text { Uberlândia-MG } & \text { v. 22, n. } 83 & \text { out./2021 p. 86-103 } & \text { Página } 102\end{array}$


HILGERT, I. H. Estruturação de banco de dados georreferenciados para a gestão integrada do saneamento básico na cidade de Arroio do meio/RS. Centro Universitário UNIVATES, 2014. Disponível em: //hdl.handle.net/10737/631. Acesso: 8 jan. 2019.

INSTITUTO BRASILEIRO DE GEOGRAFIA E ESTATÍSTICA. Censo Demográfico 2000 Características Gerais da População. Resultados da Amostra. Rio de Janeiro: IBGE, 2002. Disponível em: https://sidra.ibge.gov.br/pesquisa/censo-demografico/demografico-2000/universo. Acesso em: 5 mai. 2019.

INSTITUTO BRASILEIRO DE GEOGRAFIA E ESTATÍSTICA. Censo Demográfico 2010 -

Características Gerais da População. Resultados da Amostra. Rio de Janeiro: IBGE, 2012. Disponível em: https://sidra.ibge.gov.br/pesquisa/censo-demografico/demografico-2010/universo-caracteristicasda-populacao-e-dos-domicilios. Acesso em: 5 mai. 2019.

INSTITUTO TRATA BRASIL. Ranking do Saneamento, Instituto Trata Brasil, resultados com base no SNIS 2017. São Paulo, 2019.

ORGANIZAÇÃO MUNDIAL DA SAÚDE. Progress on drinking water, sanitation and hygiene: 2017 Update and SDG Baselines. Geneva: World Health Organization (WHO) and the UNITED NATIONS CHILDREN'S FUND, 2017. Licence: CC BY-NC-SA 3.0 IGO.

PARÁ. Lei no 7.731 de 20 de setembro de 2013. Dispõe sobre a Política Estadual de Saneamento Básico e dá outras providências. Disponível em: https://www.semas.pa.gov.br/2013/09/23/l-e-i-no-7731-de-20-de-setembro-de-2013-publicado-no-doe-no-32-486-de-23092013/. Acesso em: 28 ago. 2019.

SECRETARIA MUNICIPAL DE SANEAMENTO - SESAN. Informações gerais sobre coleta de resíduos sólidos. Belém, 2019.

SILVA, K. R. M. Sistema de Esgoto da Bacia do Una em Belém do Pará. Belém: UFPA, TCC (Engenharia Civil). 2001.

SISTEMA NACIONAL DE INFORMAÇÕES SOBRE SANEAMENTO - SNIS (Brasil). Diagnóstico dos serviços de água e esgoto. 2017. Disponível em: https://www.snis.gov.br. Acesso em: 15 set. 2019.

Recebido em: 15/07/2020

Aceito para publicação em: 01/03/2021 